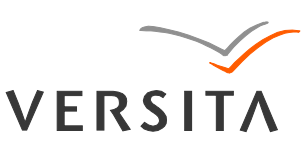

GEOCHRONOMETRIA 39(4) 2012: 268-275

DOI 10.2478/s13386-012-0013-5

Available online at

www.springerlink.com

\title{
LUMINESCENCE DATING STUDIES OF YEŞILOVA HOYUK
}

\author{
ELÇIN EKDAL ${ }^{1}$, ARZU EGE ${ }^{2}$, TURGAY KARALI ${ }^{1}$ and ZAFER DERIN ${ }^{3}$ \\ ${ }^{1}$ Ege University, Institute of Nuclear Sciences, 35100, Bornova-Izmir, Turkey \\ ${ }^{2}$ Celal Bayar University, Faculty of Art and Science, Physics Department, 45100, Muradiye-Manisa, Turkey \\ ${ }^{3}$ Ege University, Faculty of Letters, Department of Archaeology, 35100, Bornova- Izmir, Turkey
}

Received 29 July 2011

Accepted 9 May 2012

\begin{abstract}
Ceramic findings collected from Yeşilova Hoyuk located in Izmir were dated using the thermoluminescence dating technique. The area is of significant archaeological importance since it is the first prehistoric settlement in Izmir. Recent archeological observations suggest that human occupation of the region took place about 8500 years ago comparing to previously determined dates of 5000 years.

Three samples collected from the same archaeological layer (Neolithic period) in Yeşilova Hoyuk were dated using the thermoluminescence method. Archaeological doses (AD) were obtained by single aliquot regenerative dose method (SAR) for thermoluminescence (TL) using coarse grain quartz minerals extracted from samples. Thick and thin $\mathrm{Al}_{2} \mathrm{O}_{3}: \mathrm{C}$ thermoluminescence dosimeters (TLD) were used to determine the annual dose rate.

The archaeological doses were found to vary from $25.91 \pm 0.78$ to $26.82 \pm 0.68 \mathrm{~Gy}$, and the annual doses were found to be between $3.34 \pm 0.24$ and $3.47 \pm 0.24 \mathrm{mGy} / \mathrm{a}$. The ages obtained for the samples were determined to be $6000 \pm 830 \mathrm{BC}, 5740 \pm 670 \mathrm{BC}$ and $5460 \pm 740$ years for samples ND1, ND2 and ND3, respectively, which supports the prediction of archeologist that the sampling layer dates from the Neolithic period.
\end{abstract}

Keywords: TL dating, archaeology, Neolithic period, quartz, $\mathrm{Al}_{2} \mathrm{O}_{3}: \mathrm{C}$.

\section{INTRODUCTION}

Izmir has been a meeting point of Aegean, Mediterranean and Balkan civilizations, as well as domestic cultures of the Southeast Anatolia. Given its strategic location, inter-regional migration, invasion and trade have played an important role in the development of the area during the earliest times. Izmir should not only be seen as a cultural transition zone, but also as a region influenced by very large geographical areas in cultural history. The city is one of the oldest settlements of the Mediterranean basin. The recent discovery (in 2003) of Yesilova Hoyuk,

Corresponding author: T. Karali

e-mail: turgay.karali@ege.edu.tr situated in the plain of Bornova, reset the starting date of the city's history further back than was previously known.

The settlement in Yesilova Hoyuk includes three cultural layers. Starting from the surface soil, these layers were put into groups as follows; the first layer: Early Bronze Age-Roman period, second layer: Chalcolithic period (2 levels) and the third layer: (8 levels) Neolithic Period, from which samples were collected. The Neolithic settlement, at a depth of 4 meters under the surface level, had started in the Neolithic period and reached its zenith towards the end of the Neolithic. The same settlement existed partially through the Chalcolithic period. Accordingly, Yesilova Hoyuk experienced settlement 
spanning at least fifteen hundred years. It was the longest and thickest cultural level in which there were traces of mud and clay deposits due to the flooding from nearby streams (Derin, 2007).

Findings obtained from the settlement area indicate a community which regularly consumed sea-foods such as mussels and snails, and that their activities were, at least partially, also directed towards agricultural production. Numerous bone fragments provide evidence for extensive hunting of animals in the neighborhood, principally wild cattle, pigs and deer, which were consumed as food. The Yesilova Hoyuk had rich water resources and a generous flora, which were highly important conditions for the subsistence of Neolithic people (Derin et al., 2010).

The thermoluminescence dating method has been used to determine the age of Neolithic ceramic samples collected from the Yesilova Hoyuk. The method is the most preferred dating method for fired or heated materials such as ceramic, pottery and bricks. The archeological age is determined from the ratio of the archaeological dose, which is the total accumulated dose following the last heating of the sample, to annual dose originating from the cosmic rays and naturally occurring radioisotopes ( $\mathrm{K}, \mathrm{U}$ and $\mathrm{Th})$ in the surrounding soil and the material itself.

Quartz is the most common mineral in the earth's crust after the feldspar. Nearly $100 \%$ of its composition consists of $\mathrm{SiO}_{2}\left(>97.8 \mathrm{wt} \% \mathrm{SiO}_{2}\right)$. It is the main component of nearly all volcanic rocks and secondary material in sediments. Thermoluminescence dating of quartz has been extensively used since the early 1970s (Sampson and Fleming, 1972; Aitken, 1985; Hütt et al., 2001; Göksu et al., 2001; Benea et al., 2007; Veronese et al., 2008).

The mineral particle size is of great importance in studies of luminescence dating. There are two different particle sizes used in luminescence dating, namely coarse grains $(>90 \mu \mathrm{m})$ and fine grains $(4-11 \mu \mathrm{m})$. The use of coarse grained minerals has some advantages such as the elimination of the effects of alpha particles. In addition coarse grains contain single mineral, which are well understood in terms of their luminescence characteristics. However, many ceramic samples do not have sufficient amount of coarse grained minerals (Barnett, 2000; Feathers, 2003).

Single aliquot regenerative dose method for thermally stimulated luminescence dating was first proposed by Wintle and Huntley (1979) in order to determine the archaeological doses. The application of this method for TL (SAR TL) was proposed by Hong et al. (2006). In this method, first, the natural TL signal of the sample is measured. Then the growth curve is obtained by exposing the sample to known regeneration doses with an appropriate radiation source in the laboratory (Hong et al., 2008; Song et al., 2009). Archaeological dose is then taken as the value of the dose given to a sample so as to restore the natural TL signal. The advantage of this method is that the natural TL signal can easily be assessed even for the older samples, in which the natural TL signal is on the corresponding portion of the non-linear growth curve (Liritzis, 2000). The method is reliable since no extrapolation in the growth curve is required to determine the archaeological dose (Duller, 1994; Lepper et al., 2003). Multiple aliquots of the sample may also be used in TL dating; however, many sample discs considered to be identical to each other have to be used, while only one disc is sufficient to determine archaeological dose in single aliquot method (Murray and Wintle, 2000; Murray and Wintle, 2003). In addition, the SAR method does not require any normalization in order to correct mass and sensitivity difference between multiple discs.

In this study, the archeological age of samples collected from the Yesilova Hoyuk in Izmir were determined using coarse grains of quartz mineral extracted from the fired ceramics after applying the SAR TL protocol. This is the first attempt to determine the archeological age of the site using the luminescence dating technique.

\section{MATERIAL AND METHOD}

\section{Sampling site}

Environmental variables were key factors determining the siting and development of settlements in historical times. The favorable climatic and geographical conditions at Yesilova Hoyuk made it a convenient and advantageous location for human habitation compared to other cities. The remains belong to the oldest settlements at the center of Izmir are found in Yesilova Hoyuk $\left(38^{\circ} 26^{\prime} 29^{\prime \prime} \mathrm{N}-27^{\circ} 12^{\prime} 51^{\prime \prime}\right.$ E) (Fig. 1).

The plain has rich water sources fed from many streams. Thick alluvial layers have accumulated over time at the site, which are the product of flooding by the streams running over the plain. In a similar way, Yesilova Hoyuk, which is buried by a thick layer of alluvial deposits, is a mound-type settlement. The layer corresponding to the Neolithic period in which the samples were taken is about 3 meters in depth. It is the thickest and longest cultural times in Yesilova.

\section{Sampling and sample preparation}

In thermoluminescence dating, the natural TL signal of the sample should be reset by heating at high temperatures (Aitken, 1985). The ceramic samples were collected from the layer considered to be from the Neolithic period of human occupation as estimated by archaeologist at Yesilova Hoyuk (III. Layer shown in Fig. 2). They are handmade, good quality pottery. The colors of these samples are reddish, revealing that they were well fired. Therefore, the samples used in TL dating were collected from this layer.

Ceramic samples include different kind of crystalline inclusions such as quartz, feldspar and zircon. These minerals behave like a dosimeter for naturally occurring radiation of internal and environmental radioactivity. In 


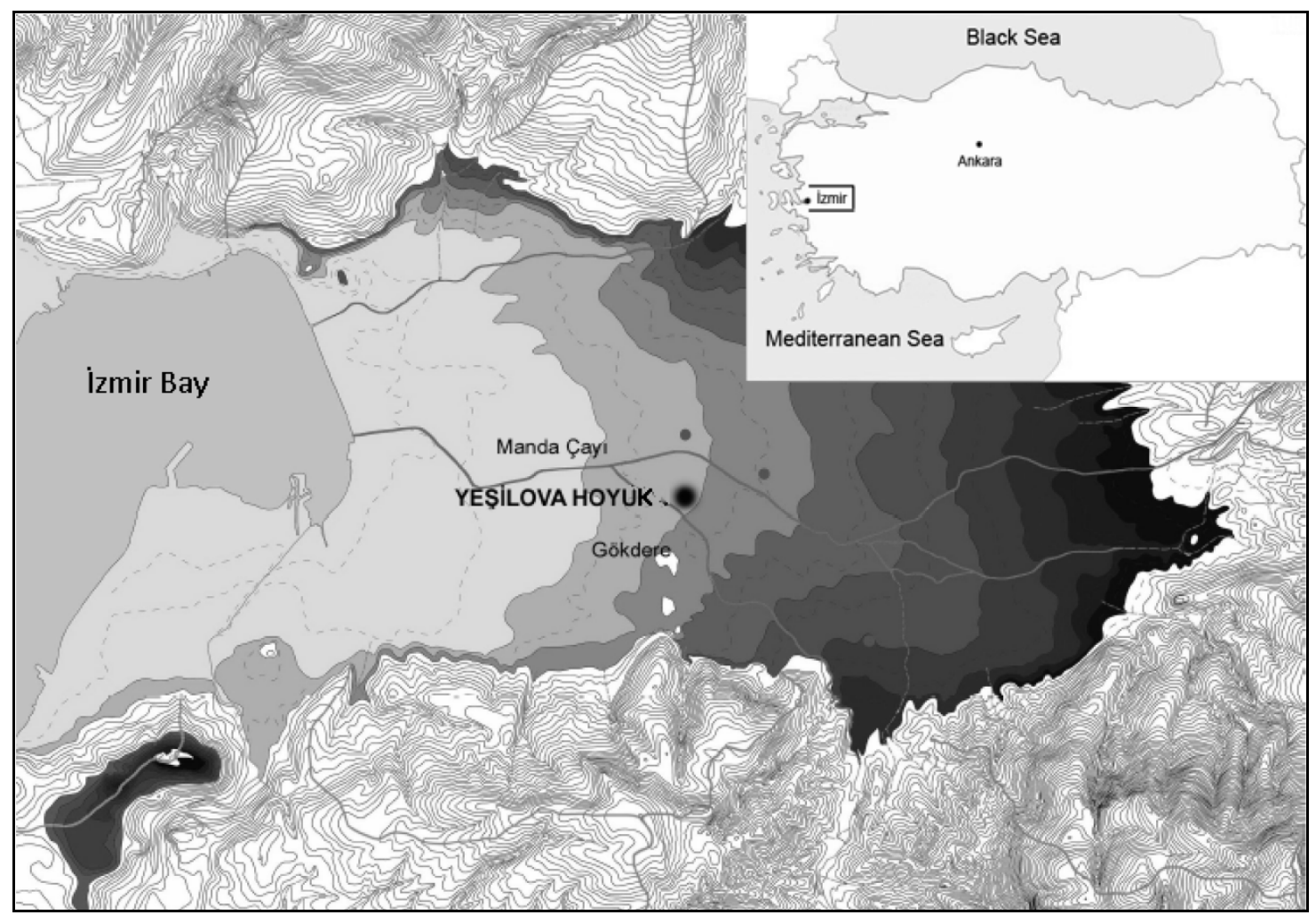

Fig. 1. Location of the Yeşilova Hoyuk, Izmir, Turkey. The map shows the geographic surface pattern of the area.

this study coarse grain quartz minerals extracted from samples, ranging from 140 to $250 \mu \mathrm{m}$ in size, were used, and all preparation procedure was done under dim red light. During sample preparation, the outer surface of the samples $(\sim 2 \mathrm{~mm})$ was firstly removed mechanically to eliminate beta radiation dose contribution from surrounding soil to the sample. The remaining inner part of the samples were gently crushed and sieved. The coarse grains obtained were washed in $10 \% \mathrm{HCl}$ acid and treated with $\mathrm{H}_{2} \mathrm{O}_{2}$ to remove carbonates and organic materials, respectively. Quartz grains were extracted by density separation using sodium poly-tungstate solutions of 2.60 and $2.75 \mathrm{~g} \cdot \mathrm{cm}^{-3}$. Then they were etched with $40 \% \mathrm{HF}$ acid for 40 minutes in order to remove the alpha particles dose contribution, and washed with dilute $\mathrm{HCl}$ acid to remove any precipitated fluorides. After each chemical procedure, the extracts were washed with pure water and dried. Finally, samples were wet sieved and dried again. These treatments were applied to eliminate some undesirable materials and to obtain pure quartz minerals. Finally, extracted quartz minerals were placed on stainless steel discs of $10 \mathrm{~mm}$ in diameter (Aitken, 1985; Benea et al., 2007; Veronese et al., 2008).

\section{Determination of Archaeological Dose}

Archaeological dose was determined by single aliquot regeneration (SAR) dose method, which decreases the error arising from sample inhomogeneity among the discs

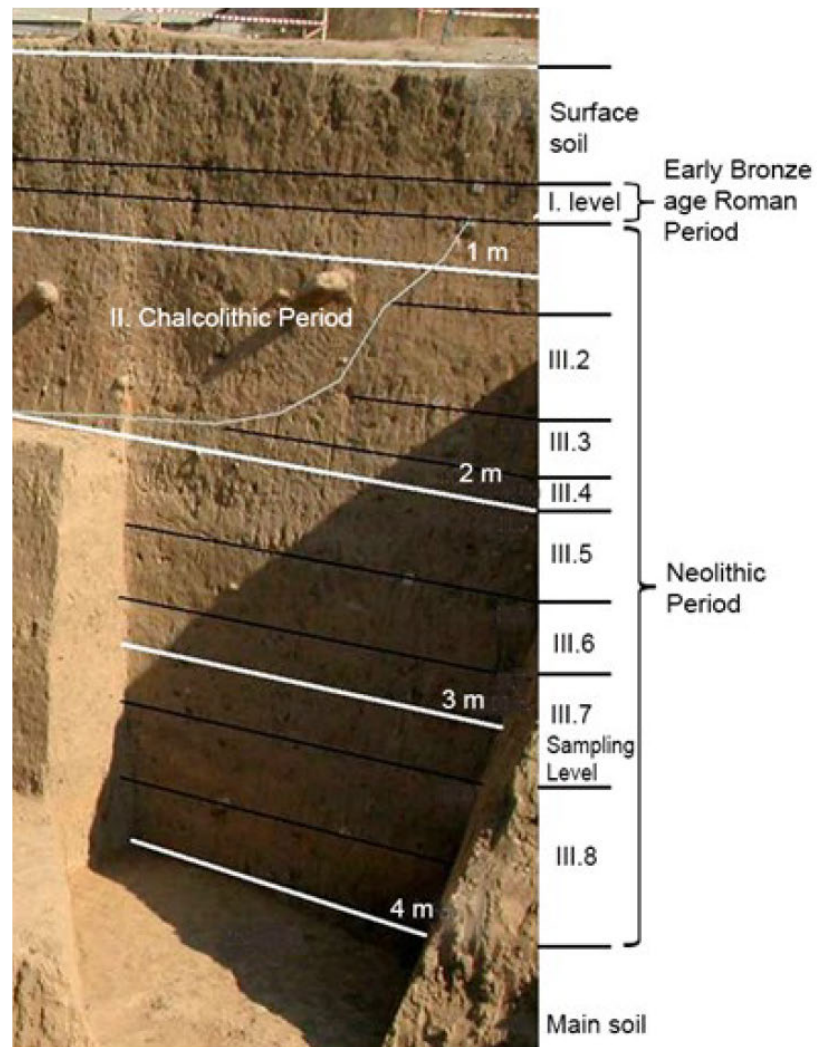

Fig. 2. Horizontal profile of the site in Yeşilova Hoyuk, showing the sampling level. 
(Murray and Wintle, 2003; Hong et al., 2006). The dose can be determined with improved precision as each aliquot is self-normalizing. Another important advantage of the method is that the mass of sample required is reduced to a minimum, which may be critical in certain situations. On the other hand, the method has a drawback due to a probable change of the sample sensitivity during irradiation and heating cycles (Hong et al, 2008; Wallinga et al. 2000).

In order to be able to choose a stable temperature interval for the glow curve of the samples the plateau test was performed (Aitken, 1985). For this, the natural TL glow curve is compared with the glow curve after laboratory irradiation. The region in which a plateau is observed is thermally stable since the natural TL signal and signal from laboratory irradiated sample have a constant ratio. The archaeological dose was determined by integrating the plateau region of the corresponding glow curves, and the background signals recorded after each measurement subtracted.

\section{Determination of Annual Dose Rate}

One of the most important processes in luminescence dating is to determine the radiation dose to which the sample has been exposed per year, namely annual dose rate. In coarse grain method, this is the product of three components; i) beta dose contribution from the ceramic samples itself, ii) gamma dose contribution from the associate soil, and iii) some contribution from the cosmic radiation. TLD measurements were used to determine annual dose rate.

In TLD measurements, thin $\mathrm{Al}_{2} \mathrm{O}_{3}: \mathrm{C}$ and thick $\mathrm{Al}_{2} \mathrm{O}_{3}: \mathrm{C}$ TL dosimeters were used to assess beta and gamma - cosmic radiation contribution to annual dose, respectively.

\section{TLD measurements}

The gamma and cosmic radiation dose contribution to annual dose rate was determined using thick $\mathrm{Al}_{2} \mathrm{O}_{3}: \mathrm{C}$ dosimeter. In order to remove any existing charge from traps, dosimeters were first annealed at $900^{\circ} \mathrm{C}$ for 15 minutes. Then, they were embedded into a $30 \mathrm{~cm}$ deep hole at the sampling location within a plastic tube for 12 months to take into account seasonal variations.

The contribution of beta particles present in quartz crystals to the annual dose was determined using thin $\mathrm{Al}_{2} \mathrm{O}_{3}: \mathrm{C}$ dosimeters (Göksu et al., 1999). The dosimeters were annealed at $400^{\circ} \mathrm{C}$ for 30 minutes to remove any existing trapped charges. Two grams of dried archaeological samples were powdered and placed in plastic sample holders with quartz to ensure electronic equilibrium. Since the holders are fully filled by the sample, it can be accepted as beta thick. In order to block the alpha particles from uranium and thorium series the holder was covered with a thin Mylar sheet (density $1.0 \mathrm{mg} / \mathrm{cm}^{2}$ ) and then the dosimeters were placed on top of the holders.
They were kept in a lead shielded chamber for 2 months in order to protect from background gamma rays. To evaluate the background radiation in the chamber, pure quartz powder sample was also used under the same conditions (Göksu and Schewenk, 2000; Göksu et al., 2001). After two months of storage time, accumulated dose of both thin $\mathrm{Al}_{2} \mathrm{O}_{3}: \mathrm{C}$ dosimeters and pure quartz powder were determined by recording their TL glow curves. Since the TL signals from pure quartz is due to the background beta and gamma radiations in the lead chamber they were subtracted from the accumulated dose of $\mathrm{Al}_{2} \mathrm{O}_{3}: \mathrm{C}$ dosimeters in order to assess the beta dose contribution $\left(D_{\beta}\right)$ from the sample. All of these measurements were conducted in $2 \pi$ geometry; therefore, the results were multiplied by a factor of 2 in order to simulate the beta radiation field of the sample (Veronese et al., 2008).

Approximately 6-10 $\mu \mathrm{m}$ of the outer surface of the coarse grain quartz minerals was etched during the chemical procedure (Bell and Zimmermann, 1978; Aitken, 1985). Because of the elimination of the outer surface being exposed to external alpha particles, alpha radiation dose contribution to the annual dose was neglected.

\section{Water content in the samples}

The water content of a sample is an important parameter because of water dose absorption. Water in archaeological samples absorbs some of the radiation that prevents part of the radiation energy reaching to quartz grains. For this reason dose rate in dry sample may be higher than the humid sample. This may cause underestimation of age. Therefore, the percentage of water in the samples $\left(\mathrm{W}_{\%}\right)$ was determined in the laboratory. Eventually, in order to obtain the exact dose rate of beta and gamma radiation to the sample, the measured values were corrected by multiplying with convenient correction factors (Aitken, 1985). Therefore the measured value of $D_{\beta}$ and $\mathrm{D}_{\gamma}$ dose must be multiplied by appropriate correction factor so that the correct beta dose rate absorbed by the quartz grains is obtained. On the other hand, measured value of $D_{\gamma+c}$ doses do not require any correction since the dosimeters were buried to sampling point in which they were exposed to the all seasonal variations.

\section{TL Measurements}

All TL curves were recorded using a Harshaw TLD 3500 reader in nitrogen atmosphere at a heating rate of $2^{\circ} \mathrm{C} \cdot \mathrm{s}^{-1}$. Background measurements were conducted after each measurement and subtracted from individual TL measurements. In order to protect the photomultiplier tube from blackbody radiation, a $3 \mathrm{~mm}$ heat absorbent filter (Schott KG-1) has been placed in front of the tube. Irradiations were carried out using ${ }^{90} \mathrm{Sr} /{ }^{90} \mathrm{Y}$ beta source. The equivalent dose rates being exposed to samples were calibrated using $\mathrm{Al}_{2} \mathrm{O}_{3}: \mathrm{C}$ dosimeters and pure quartz samples irradiated at Çekmece Nuclear Research and 
Education Center, Secondary Standard Dosimetry Laboratory. Thus, it was determined that the beta source at the laboratory delivered an equivalent dose rate of $3.10 \pm 0.15$, $5.10 \pm 0.16$ and $5.30 \pm 0.60 \mathrm{mGy} \cdot \mathrm{s}^{-1}$ for thick, thin $\mathrm{Al}_{2} \mathrm{O}_{3}: \mathrm{C}$ dosimeters and quartz, respectively.

\section{RESULTS AND DISCUSSION}

The archaeological dose was determined by using the single aliquot regeneration dose procedure for TL measurements (Hong et al. 2006). In this study three samples collected from the same archaeological layer of the site were used, and five aliquots were prepared for each sample in order to reduce the statistical error.

Firstly, the natural TL glow curves were recorded and compared with the glow curves obtained after laboratory irradiations of the samples. The temperature region in which a plateau is observed is thermally stable since the natural TL signal and signal from laboratory irradiated sample have a constant ratio. Therefore, the temperature region from 275 to $300^{\circ} \mathrm{C}$ was considered as a plateau region in this study (Fig. 3).

Later, dose response experiments were conducted for each sample, obtaining a linear response from 2.4 to 38.4 Gy. For a double check, we have also conducted given to measured dose experiments, and observed a unity, revealing that there were no sensitivity changes due to preheating and irradiation cycle. In order to determine the archeological dose, TL experiments were conducted on five aliquots prepared from each sample. A $220^{\circ} \mathrm{C}$ preheat temperature was applied to the samples in order to suppress the unstable low temperature TL signals. The natural TL signals of quartz minerals extracted from the samples were recorded. In order to determine the equiva-

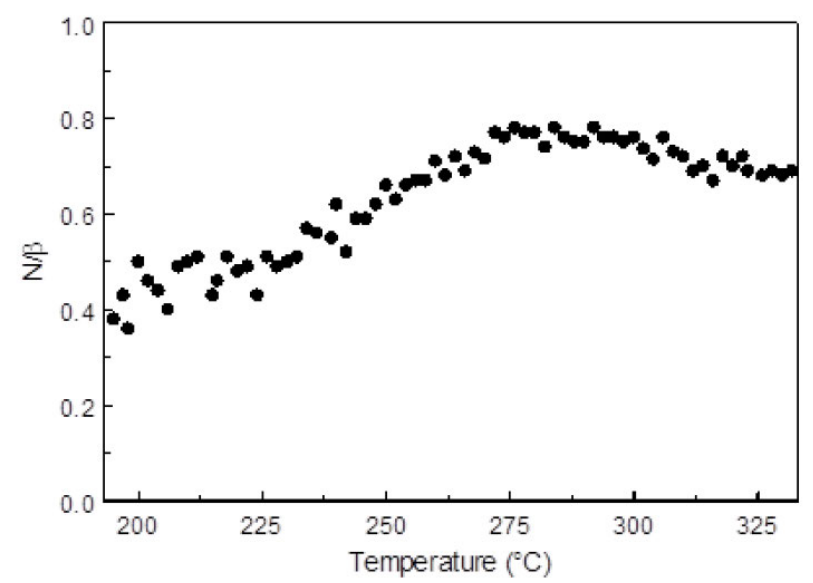

Fig. 3. A plot of the plateau curve as obtained by comparing the shape of the natural glow curve with the shape of the regenerated one. lent dose of these signals, artificially induced TL signals were recorded after the samples were irradiated with different laboratory doses. Fig. 4 represents the glow curves recorded for natural and regenerated TL. Later, the TL signals between 275 and $300^{\circ} \mathrm{C}$, corresponding to the plateau region, were integrated after subtracting the background signals, collected after each experiment under the same conditions. The integrated TL signals were plotted against regenerative doses in order to produce growth curves for each sample, in which archaeological doses were determined (Fig. 5). The archaeological doses were found to be $27.70 \pm 1.17,27.55 \pm 1.15$ and $26.50 \pm 1.08$ Gy for ND1, ND2 and ND3 samples, respectively.

Gamma $\left(D_{\gamma}\right)$ and cosmic $\left(D_{c}\right)$ radiation dose contribution to annual dose were determined to be $1.67 \pm 0.06$ mGy/a by using thick $\mathrm{Al}_{2} \mathrm{O}_{3}$ : C TL dosimeters. Beta dose contribution $\left(D_{\beta}\right)$ to annual dose from the samples itself were also determined as $2.50 \pm 0,54,2.62 \pm 0.49$ and $2.54 \pm 0.49 \mathrm{mGy} / \mathrm{a}$ by using thin $\mathrm{Al}_{2} \mathrm{O}_{3}: \mathrm{C}$ TL dosimeters for dried ND1, ND2 and ND3 samples, respectively.

The saturation water contents of the samples (W\%) were determined to be $35 \pm 0.42$ for ND1, $32 \pm 0.38$ for ND2 and $28 \pm 0.37$ for ND3 samples. The sampling site was exposed to flooding several times from nearby rivers through history (Derin et al., 2010); therefore, the fractional uptake $\mathrm{F}$ was considered to be $0.8 \pm 0.2$ according to these climatic factors of the site (Aitken, 1985). The moisture corrected beta dose rate was calculated as $1.85 \pm 0.28,1.99 \pm 0.24$ and $2.00 \pm 0.28 \mathrm{mG} /$ a using equations given by Adamiec and Aitken (1998) for ND1, ND2 and ND3 samples, respectively.

The annual dose for coarse grain samples in the current study was determined from the following equation (Aitken 1998):

Annual Dose $=0.90 \mathrm{D}_{\beta}+\mathrm{D}_{\gamma}+\mathrm{D}_{\mathrm{c}}$

and they were determined to be $3.34 \pm 0.24$ for ND1, $3.46 \pm 0.21$ for ND2 and $3.47 \pm 0.24 \mathrm{mGy} / \mathrm{a}$. Using the age equation;

Age $=$ Archaeological Dose/Annual Dose

the ages of the samples were calculated to be $6000 \pm 830$, $5740 \pm 670$ and $5460 \pm 740 \mathrm{yr}$ BC for ND1, ND2 and ND3, respectively. Uncertainties obtained are in good agreement with literature (Hütt et al., 2001; Benea et al. 2007; Veronese et al. 2008, Meriç et al. 2009). The obtained results were summarized in Table 1.

The burnt wooden samples obtained from the same Neolithic level of Yeşilova were dated using radiocarbon dating method by Dr. Bernhard Weninger at the University of Köln. The date of the sample was determined to be $7505 \pm 37{ }^{14} \mathrm{C}$ BP (6440-6360 (63.9\%) and 6290-6270 (4.3\%) cal BC). (Derin et al., 2010). 

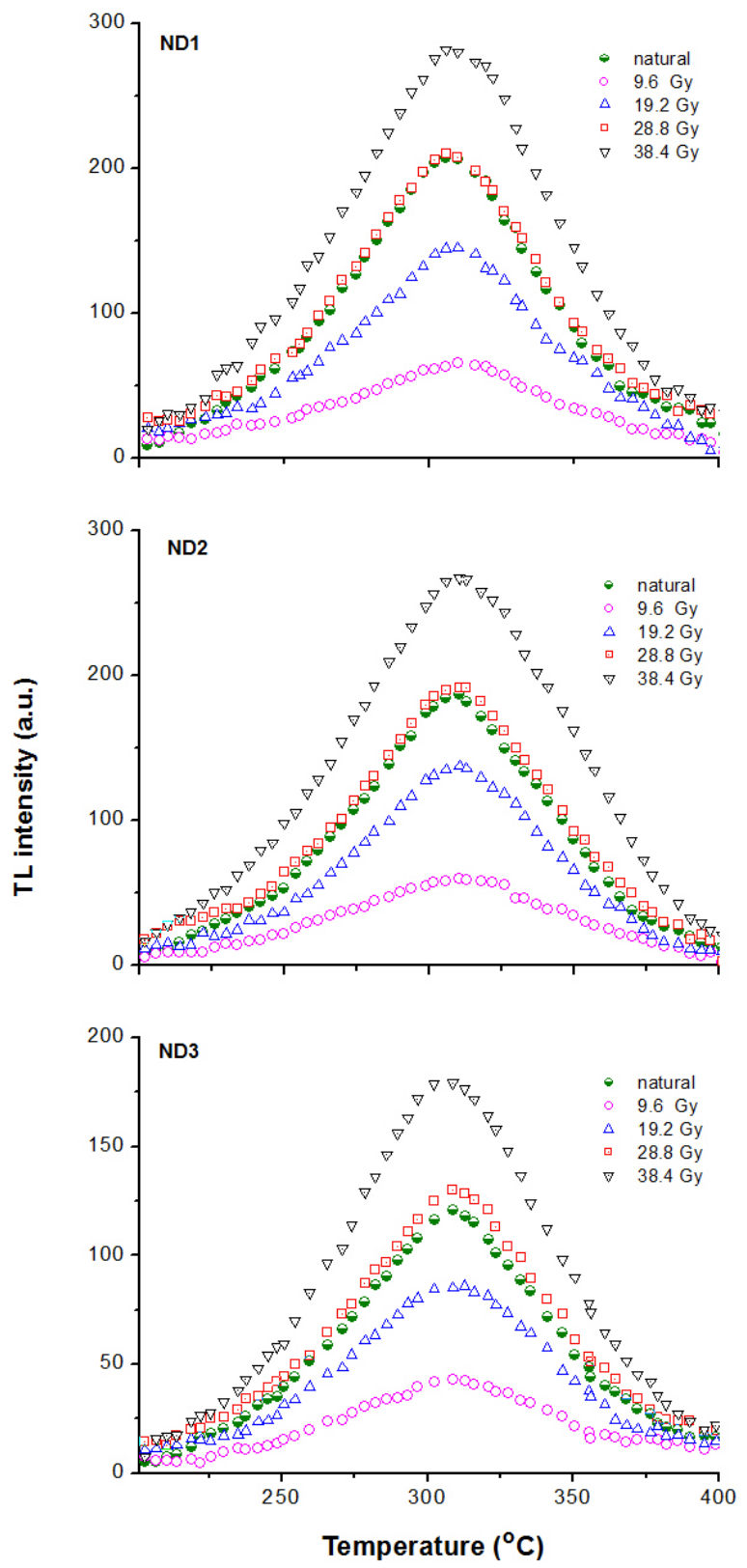

Fig. 4. Natural and regenerated TL glow curves of quartz grains ex-
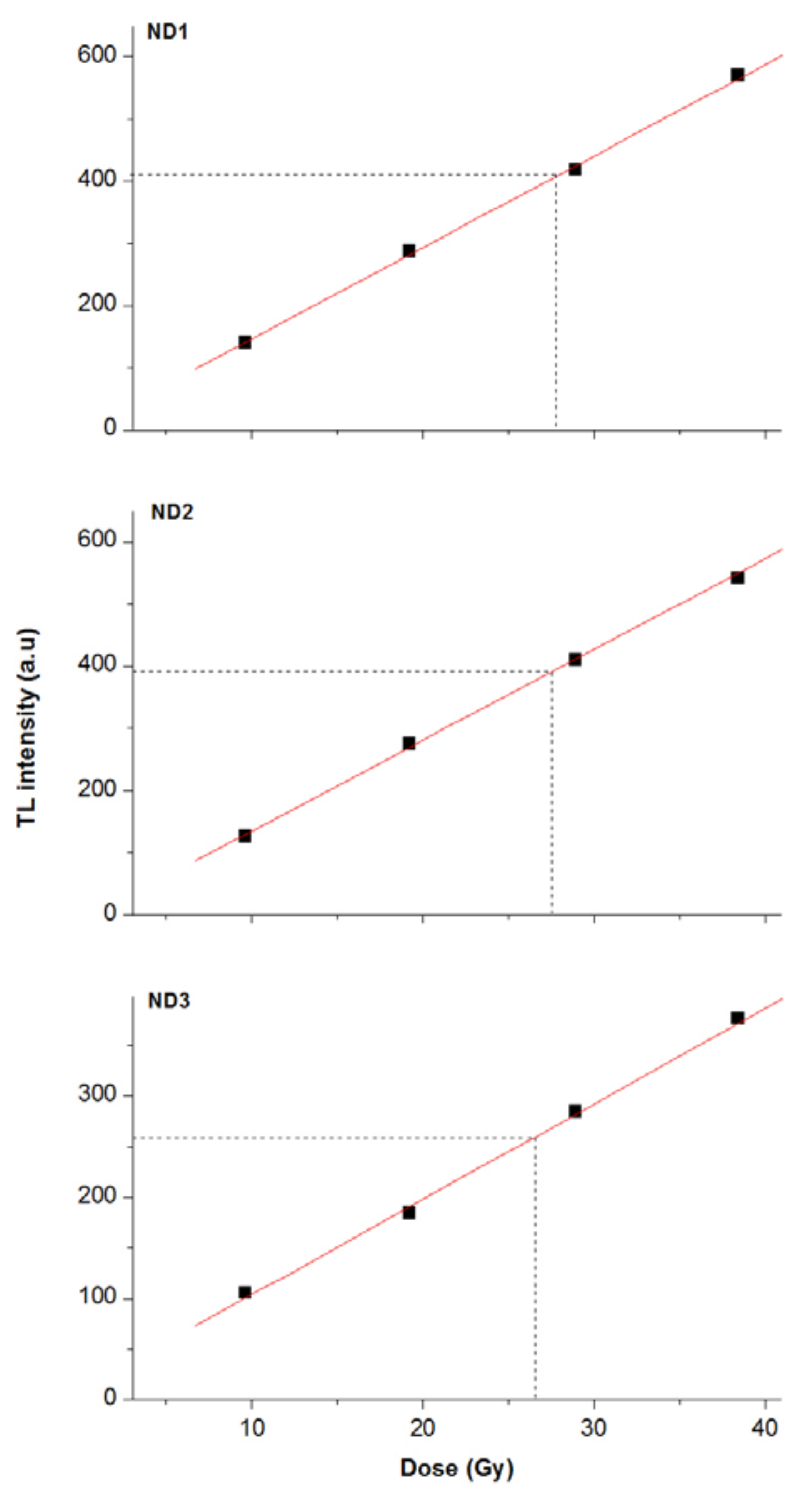

Fig. 5. Growth curves used in determining the archaeological dose of the quartz samples using SAR TL technique.

Table 1. Results of calculated archaeological dose, annual dose rates and ages.

\begin{tabular}{lccccc}
\hline Sample ID & $\begin{array}{c}\mathbf{D}_{\beta} \\
\text { (mGy/a) }\end{array}$ & $\begin{array}{c}D_{\mathbf{y}+\mathrm{c}} \\
(\mathrm{mGy} / \mathrm{a})\end{array}$ & $\begin{array}{c}\text { Total Annual Dose } \\
\text { (mGy/a) }\end{array}$ & $\begin{array}{c}\text { Archaeological } \\
\text { Dose (Gy) }\end{array}$ & $\begin{array}{c}\text { Age } \\
(\mathrm{yr} \mathrm{BC})\end{array}$ \\
\hline ND1 & $1.85 \pm 0.28$ & $1.67 \pm 0.06$ & $3.34 \pm 0.24$ & $26.77 \pm 0.84$ & $6000 \pm 830$ \\
ND2 & $1.99 \pm 0.24$ & $1.67 \pm 0.06$ & $3.46 \pm 0.21$ & $26.82 \pm 0.68$ & $5740 \pm 670$ \\
ND3 & $2.00 \pm 0.28$ & $1.67 \pm 0.06$ & $3.47 \pm 0.24$ & $25.91 \pm 0.78$ & $5460 \pm 740$ \\
\hline
\end{tabular}




\section{CONCLUSION}

The historical development of Izmir city has been clarified through the Yeşilova Hoyuk excavations and dating studies. The discovery of the Yeşilova Hoyuk changed the date of first human occupation of the city, which was previously known to be about $5000 \mathrm{BP}$.

In this study, the archeological samples collected from the Yeşilova Hoyuk, which belong to the Neolithic period, were dated using the thermoluminescence dating technique. Coarse grained quartz minerals extracted from archeological ceramics and the single aliquot regenerative dose method were used to determine archaeological dose. In addition, the annual dose was determined using thin and thick $\mathrm{Al}_{2} \mathrm{O}_{3}: \mathrm{C}$ TL dosimeters.

The main sources of uncertainty, which were calculated using the error propagation rules and the suggestions of Aitken (1985), are the results of the manual irradiator and manual TLD reader. On the other hand, confidence in the TL dates is given by their close correspondence with radiocarbon dates obtained for the same occupation levels. Therefore, by comparing the radiocarbon and TL ages in the study region, it is reasonable to express that there is a good agreement between the obtained ages and also that of the archaeologists' prediction.

To the best of our knowledge, no other luminescence dating study has been reported in this region thus far, although there exist some luminescence dating studies conducted on archeological samples from different archeological sites (Meriç et al. 2009; Kıyak et al., 2010). Therefore, the present work was the first application of the thermoluminescence dating technique for the site. It is believed that the results obtained in this study may contribute to the promotion of the luminescence dating technique and supply valuable information for further studies in Yeşilova Hoyuk.

\section{ACKNOWLEDGEMENTS}

The work described here was financially supported by grants from the Scientific and Technical Research Council of Turkey (TÜBİTAK- Contract No: TBAG 104T139) and Ege University Science and Technology Research Center (EBİLTEM) Contract No: 2007/BİL/020. We would like to thank to Professor H.Y. Göksu for her valuable suggestions and contributions, and to Dr. A. Rowlands for English language editing.

\section{REFERENCES}

Adamiec G and Aitken MJ, 1998. Dose-rate conversion factors: update. Ancient-TL 16(2): 37-49.

Aitken MJ, 1985. Thermoluminescence Dating. Academic Press, London: $359 \mathrm{pp}$

Aitken MJ, 1998. An Introduction to Optical Dating. Oxford University Press, Oxford: $267 \mathrm{pp}$

Barnett SM, 2000. Luminescence dating pottery from later prehistoric Britain, Archaeometry 42: 431-457, DOI 10.1111/j.14754754.2000.tb00892.x.
Bell WT and Zimmermann DW, 1978. The effect of HF acid etching on the morphology of quartz inclusions for thermoluminescence dating. Archaeometry 20(1): 63-65, DOI 10.1111/j.14754754.1978.tb00213.x.

Benea V, Vandenberghe D, Timar A, van Den Haute P, Cosma C, Gligor M, Florescu C, 2007. Luminescence Dating of Neolithic Ceramics from Lumea Nouă, Romania. Geochronometria 28: 916, DOI 10.2478/v10003-007-0027-9.

Derin Z, 2007. Yeşilova Höyügü. Türkiye'de Neolitik Dönem, Yeni Kazllar, Yeni Bulgular Arkeoloji ve Sanat Yayınları, İstanbul: 377-384 (in Turkish).

Derin Z, Ay F and Caymaz T, 2010. İzmir'in Prehistorik YerleșimiYeşilova Höyüğü 2005-2006 yılı Çalışmaları (Prehistoric Settlement of Izmir - Yesilova Mount Campaign of 2005-2006). Arkeoloji Dergisi XIII -2009/1: 7-58 (in Turkish).

Duller GAT, 1994. Luminescence dating of sediments using single aliquots: new procedures. Quaternary Science Reviews 13(2): 149156, 10.1016/0277-3791(94)90041-8.

Feathers JK, 2003. Use of luminescence dating in archaeology. Measurement Science and Technology 14(9): 1493-1509, DOI 10.1088/0957-0233/14/9/302.

Göksu HY, Bulur E and Wahl W, 1999. Beta dosimetry using thin-layer $\alpha-\mathrm{Al}_{2} \mathrm{O}_{3}: \mathrm{C}$ TL detectors. Radiation Protection and Dosimetry 84(1-4): 451-455, DOI 10.1093/rpd/nci656.

Göksu HY and Schwenk P, 2000. Thermoluminescence dating of terrazzo from the monastery church of Tegernsee (Bavaria, Germany) using the $210^{\circ} \mathrm{C}$ TL peak of quartz. Radiation and Environmental Biophysics 39(4): 301-308, DOI 10.1007/s004110000063.

Göksu HY, Schwenk P and Semiochkina N, 2001. Investigation of the thermal stability of $210^{\circ} \mathrm{C}$ TL peak of quartz and dating the components of terrazzo from the monastery church of Tegernsee, $R a-$ diation Measurements 33(5): 785-792, DOI 10.1016/S13504487(01)00107-X.

Hong DG, Kim MJ, Choi JH, El-Faramawy NA and Göksu HY, 2006. Equivalent dose determination of single aliquot regenerative-dose (SAR) protocol using thermoluminescence on heated quartz. $\mathrm{Nu}$ clear Instruments and Methods in Phyiscs Research B 243(1): 174178, DOI 10.1016/j.nimb.2005.05.059.

Hong DG, Song KW and Choi JH, 2008. Tests preparatory to applying an SAR protocol to red emission quartz using thermoluminescence. Radiation Measurements 43(2-6): 758-762, DOI 10.1016/j.radmeas.2007.11.060

Hütt G, Goksu HY, Jaek I and Hiekkanen M, 2001. Luminescence dating of Somero sacristy, SW Finland using the $210^{\circ} \mathrm{C}$. Quaternary Science Reviews 20(5-9): 773-777, DOI 10.1016/S0277. 3791(00)00017-2.

Lepper K, Wilson C, Gardner J, Reneau S and Lavine A, 2003. Comparison of SAR techniques for luminescence dating of sediments derived from volcanic tuff, Quaternary Science Reviews 22(1013): 1131-1138, DOI 10.1016/S0277-3791(03)00063-5.

Liritzis I, 2000. Advances in thermo- and opto-luminescence dating of environmental materials (sedimentary deposits). Part I: Techniques, Global Nest: the International Journal 2(1): 3-27.

Meriç N, Atlıhan MA, Koşal M, Yüce ÜR and Cinaroglu A, 2009. Infrared stimulated luminescence and thermoluminescence dating of archaeological samples from Turkey. Geochronometria 34: 2531, DOI 10.2478/v10003-009-0015-3.

Murray AS and Wintle AG, 2000. Luminescence dating of quartz using an improved single-aliquot regenerative-dose protocol. Radiation Measurements 32(1): 57-73, DOI 10.1016/S1350-4487(99)00253$\mathrm{X}$.

Murray AS and Wintle AG, 2003. The single aliquot regenerative dose protocol: potential for improvements in reliability. Radiation Measurements 37(4-5): 377-381, DOI 10.1016/S13504487(03)00053-2.

Kiyak NG, Takaoglu T, Erginal AE and Ozcan H, 2010. Luminescence dating of prehistoric site of smintheion (Gulpinar) in NW Turkey. Mediterranean Archaelogy \& Archaeometry 10(4): 35-42. 
Sampson EH and Fleming SJ, 1972. Thermoluminescent dating of colombian pottery in the Yotoco style. Archaeometry 14(1): 119126, DOI 10.1111/j.1475-4754.1972.tb00056.x.

Song KW, Yun KK and Hong DG, 2009. Radiation response of thermoluminescence glow peaks seperated sing a glow curve fitting method for red emission from quartz. Radiation Measurements 44(5-6): 611-614, DOI 10.1016/j.radmeas.2009.03.034.

Veronese I, Göksu HY, Schwenk P and Herzig F, 2008. Thermoluminescence dating of a mikveh in Ichenhausen, Germany. Journal of
Environmental Radioactivity $99(4): \quad 621-630, \quad$ DOI 10.1016/j.jenvrad.2007.09.002.

Wallinga J, Murray A and Duller G, 2000. Underestimation of equivalent dose in single-aliquot optical dating of feldspars caused by preheating. Radiation Measurements 32(5-6): 691-695, DOI 10.1016/S1350-4487(00)00127-X.

Wintle AG and Huntley DJ, 1979. Themoluminescence dating of a deep-sea ocean core, Nature 279(5715): 710-712, DOI 10.1038/279710a0. 